\title{
Development of DC voltage control from wind turbines using proportions and integrals for Three-phase grid-connected inverters
}

\author{
Arckarakit Chaithanakulwat \\ Department of Electrical Engineering, Dhonburi Rajabhat University, Samutprakan, Thailand
}

\begin{tabular}{|c|c|}
\hline Article Info & ABSTRACT \\
\hline Article history: & \multirow{9}{*}{$\begin{array}{l}\text { This research article presents the method to control the DC voltage of the } \\
\text { boost converter by using a proportional-integral (PI) controller. With AC } \\
\text { voltage from a wind turbine generator, converting to DC voltage level by } \\
\text { rectifier, this DC voltage controlled by PI controller is to control boost } \\
\text { converter that sends DC links to the inverter which converting alternating } \\
\text { current voltage to direct current voltage through three-phase load and to } \\
\text { the grid-connected system. For switching the IGBTs in the inverter, } \\
\text { the PWM signal, on the hysteresis current control, is controlled by the signal } \\
\text { from the detected reference voltage based on the grid-connected system and } \\
\text { the voltage from a wind turbine generator. The tests made the comparison of } \\
\text { results from the simulation with the MATLAB/Simulink program and result } \\
\text { from the hardware on the prototype. The power quality results, such as } \\
\text { harmonic, power factor, are in acceptable ranges. }\end{array}$} \\
\hline Received Mar 18, 2019 & \\
\hline Revised Oct 30, 2019 & \\
\hline Accepted Nov 15, 2019 & \\
\hline Keywords: & \\
\hline Grid-connected & \\
\hline Hysteresis & \\
\hline Inverter & \\
\hline Proportions and integrals & \\
\hline
\end{tabular}

Copyright $\odot 2020$ Institute of Advanced Engineering and Science. All rights reserved.

\section{Corresponding Author:}

Arckarakit Chaithanakulwat, Department of Electrical Engineering,

Dhonburi Rajabhat University,

59/1, Moo 14, Sukhumvit Rd., Bang Pla Sub-district, Bang Phli District,

Samut Prakan 10540, Thailand.

Email: chaithanakul@gmail.com

\section{INTRODUCTION}

Presently, humans have studied and created inventions that can create new energy as an alternative to the user's current energy on this planet. Especially electric power is widely used energy because the process of acquiring electric energy may be made from water energy, solar energy, wind power, and geothermal energy and much more. These energies, converted into electrical energy, are pure energy and do not run out of the world. Electric power is currently an essential factor in human life and on manufacturing processes in the industry. There was a continuous effort to increase the generation of electrical power to meet the power demand requirement. Solar energy and wind energy widely use as non-conventional energy resources. Wind energy is to prove itself as a cost-effective and reliable energy resource around the world. Grid-connected systems, with constant speed wind energy systems employing induction generators, are popular methods, and they extract optimum power from the wind for single wind speed. Variable speed wind energy systems, integrated with power electronic interfaces, become popular methods because they can extract optimum power, alleviate the load peak in the drive train, smoothly the electrical power output and supply reactive power on demand [1-7]. Permanent magnet synchronous generators (PMSG) are now being used instead of induction generators, because of improved efficiency, modularity and absence of excitation current. For maximum power extraction, the speed of the turbine should vary according to the wind speed to maintain the optimum speed ratio. The modelling, simulation and experimental verification of a utilityinteractive wind energy conversion scheme with an asynchronous link comprised of a diode bridge rectifier 
and a line-commutated inverter. The control objective is to track and to extract maximum power from the wind energy system and to transfer this power to the utility $[8,9]$. The proposed project is to control the flow of energy through the DC-link to reduce the reactive energy that is burdened on the capacitors for stimulating and making more use of wind energy. The simulated results have shown that it provides good tracking power performance. The wind power generation is to use as a variable speed wind turbine that driving a doubly fed induction generator, wound synchronous field generator [10, 11]. It focused on a detailed analysis of the variable speed wind turbine PMSG with an inverter that controls the current. Modelling and suitable control strategies for overall system are developed to augment the low voltage ride-through capability of variable speed wind generator, considering recent wind farm grid code. Development of experimental testing of automatic wind power conversion systems based on synchronous permanent magnet generators [12, 13]. This work is to validate the functionality of the test bench, leading to an experiment by some principles developed in theory. The objective is to control the load connection voltages and the DC bus voltage. There are two resonant controllers, the first control is on the load connected to the DC bus, and the second control is to maintain a balance between production and consumption despite wind fluctuations and load variations. The experimental results showed that the effectiveness of the test bench is trying out in real-time the behaviour of a WECS, supplying an isolated load, and offering the maximum power tracking point for wind speed conversion system (WECS) [14, 15].

The proposed method, without the need for air density, wind speed and turbine parameters, results generated at the appropriate speed for the loop control of the vector flux-controlled rotor that controls the grid-controlled inverter system using only. Determining the optimal speed allows WECS to track the maximum energy point that created according to the change in the active power due to the change in the speed of the command generated by the controller. Vector control of the generator rectifier depends on the reference current, voltage vector, grid [16-18]. The proposed method increases the speed and accuracy of tracking at a certain point, by using energy and wind speed characteristics for various wind speeds. This focuses on the most suitable energy point and decreases speed. Tracking after the pseudo point can improve the accuracy of the algorithm and increase the tracking speed for various wind speeds. The used system consists of a sine pulse width modifier, a reverse side between the generator and the grid. The efficiency of the proposed method is analyzed in mathematics and examined by simulation, which is to find the right spot for speed control [19]. The wind energy conversion system (WECS) Gen variable speed wind turbine, with a permanent magnet type axis, is proposed. Although the conventional-type induction generator has the advantage of robust construction and maintenance-free operation, and it has drawbacks like low-power-factor and needs for an AC excitation source which is overcome by the PMG, resulting in a constant voltage and frequency. The generated PMG pressure passes to the energy converter [20, 21]. Conventionally the three stages of power conversion consist of the rectifier, boost chopper and pulse width modulation inverters that reduce power quality, resulting in overall efficiency and reliability of WECS. To reduce these barriers of conventional systems, we propose a two-step WECS drive. The maximum power point for each speed is traced using a sensor-less MPPT controller, which estimates. The MPPT controller, direct drives with ZSI and simulated in MATLAB/Simulink., has no sensors offered for WECS. By comparison results with experiments [22].

The research mentioned above has the primary purpose of controlling the speed of a three-phase generator connected to a wind turbine. This research, the main objective is to design a three-phase voltage control system that is generated by the generator and supply the power to the load. The rest of the load, the power is returned to the grid system. This research has a brief working principle as follows the voltage from the three-phase generator is converted via bridged rectifier and voltage booster to raise the supply voltage to the three-phase inverter controlled by the microcontroller, TMS320F28379D for the booster circuit, the voltage is controlled by the PI method to control the DC voltage to be stable. For the three-phase inverter, PWM modulation is controlled by using the hysteresis current control technique [23-28].

\section{DESCRIPTION OF THE PROPOSED SCHEME}

Controlling the voltage from the generator connected to the wind turbine is generally used to control the speed of the generator using the current control principle. For this research, the voltage control principle used by a boost converter scheme to control the voltage level with the PI method, which is different from the general published research. The diagram of the proposed system is as follows in Figure 1. When the AC voltage from the generator changes to a DC voltage using the rectifier circuit, it brings the current flow through the boost converter and being controlled by using the PI controller. Then it is connected to the threephase grid-connected system. When considering the inverters used for the link between wind turbines and generators that pass through the boost converter circuit, an inverter converts the DC voltage to AC to supply 
non-linear loads and to supply power to the grid system as mentioned above, therefore the inverter circuit design is essential for controlling energy and electricity to pay into the system. In this research, the inverter uses a current flow control technique.

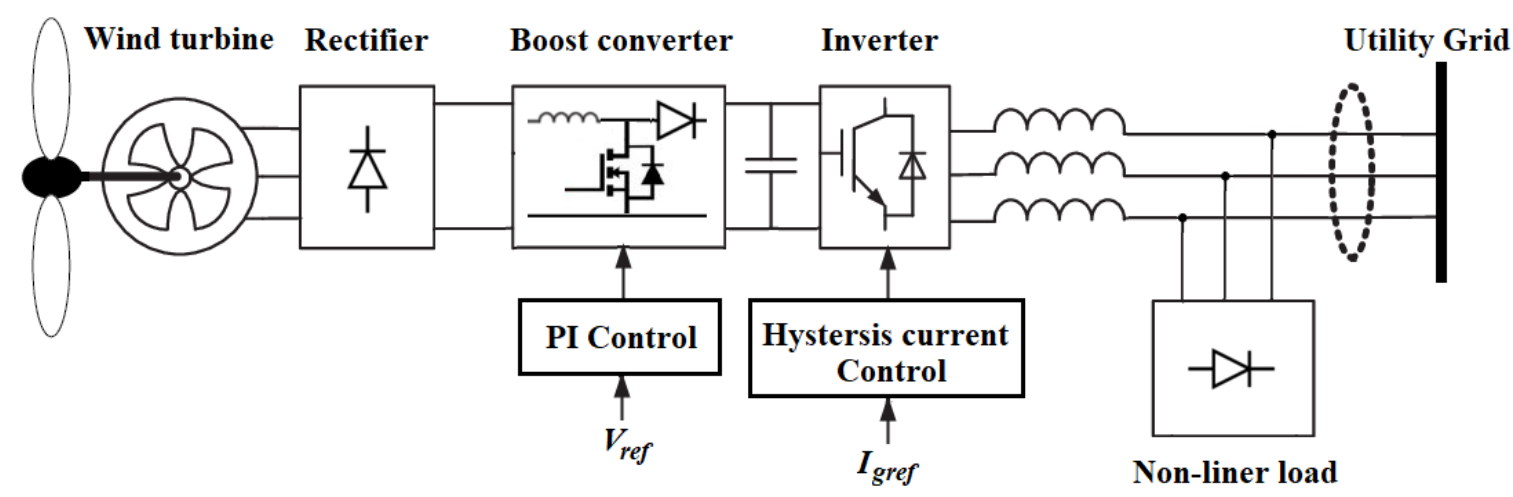

Figure 1. Proposed wind energy conversion system

\subsection{Principles of DC voltage control}

The DC voltage control uses the PI controller and P controller, to ensure that the DC voltage is constant and the AC voltage is higher than the electrical network. For this governing principle, the C2000 genus of microcontrollers uses the TMS320F28379D to detect the change in the output voltage of the boost converter, a circuit that is used to control the current flow on the switch so that the output voltage level can be displayed as shown in Figure 2. From Figure 2, the control provides a constant output voltage of the voltage at the output of the boost converter circuit and comparison $\mathrm{V}_{\text {ref, o }}$ obtained from the signal detection circuit and the required $V_{\text {constant }}$. The voltage difference is extended to $V_{\text {error }}$. After that feedback signal is sent to the proportional process and integral process, then the control signal is modulated with the sawtooth signal in the modulation.

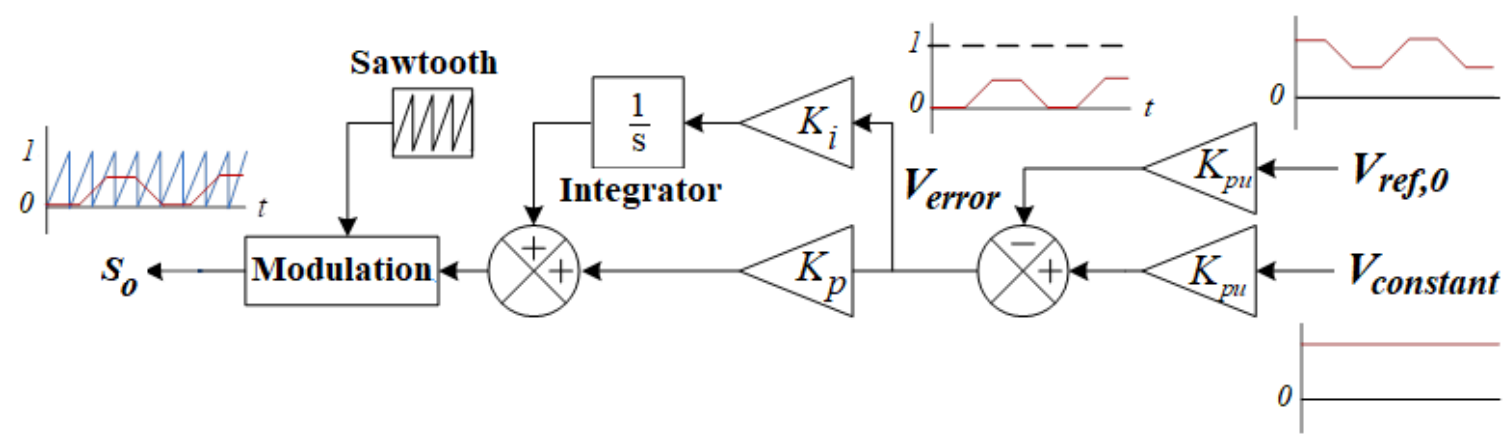

Figure 2. Proposed PI controller

The modulated signal is created as a PWM signal with a fixed period equal to the period of sawtooth voltage, and the pulse width changes according to the comparison of the result of the $V_{\text {error }}$. The amplitude of this pulse determines the time interval for the switch to bring current in the loop of the boost converter circuit. Because the output voltage on the circuit increases, the converter sends the control signal to the output voltage expansion circuit. If $\mathrm{V}_{r e f, o}$, the width of the output PWM signal decreases, resulting in greater amplitude and more current of the IGBT. If $\mathrm{V}_{\text {ref, o }}$ the width of the PWM signal makes output increases, resulting to reduce the size and to decrease the current of the IGBT. So the boost converter circuit is able to maintain the pressure constant, as a working diagram as shown in Figure 3. 


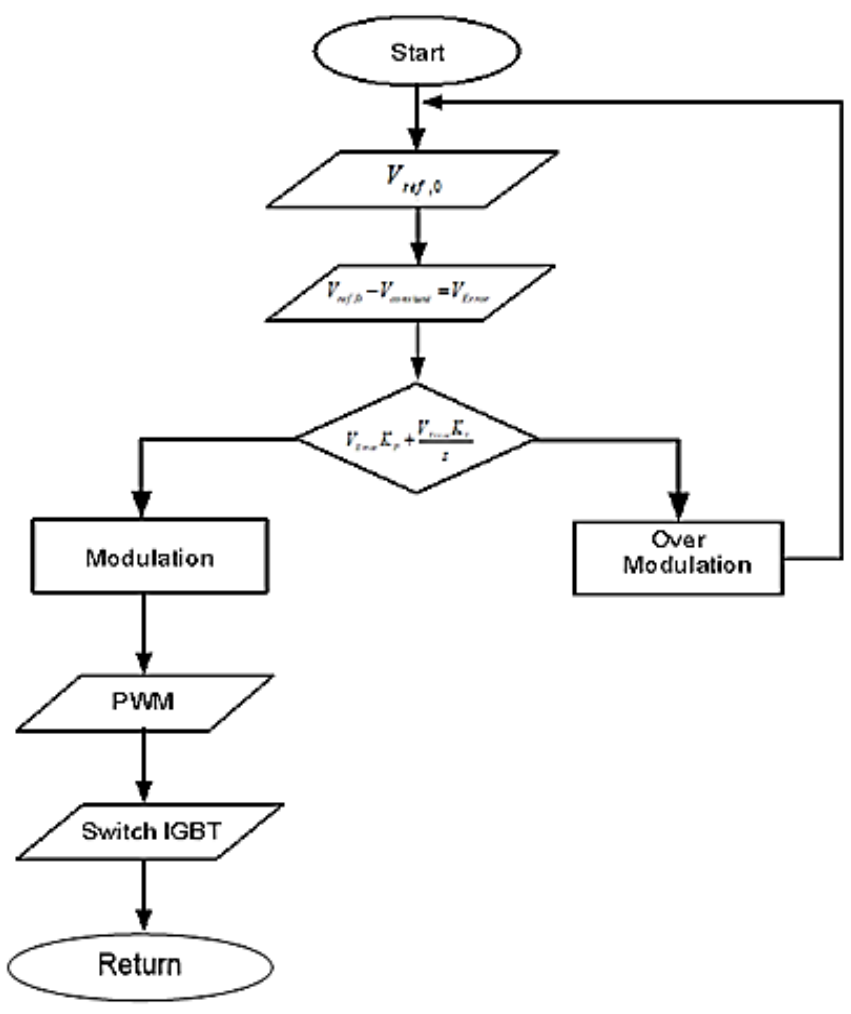

Figure 3. Diagram of process control in proportion and integration

\subsection{Boost converter control principle}

Analysis of the operation of the boost converter circuit in a stable state. Determine the working conditions of the circuit like a buck converter circuit. The analysis is as follows, the current flowing through the inductor at the same position in each period is equal and always positive. The average voltage across the inductor in each period is equal to zero, meaning that the sum of the product of the voltage across the sticky lead and time in each period is equal to zero. The capacitor is large, so the output voltage is constant, and the input power is equal to the output power. In this case, regardless of the loss due to work, all devices are ideal, thus concluding that the efficiency of the circuit is one hundred per cent. Figure 4, while the switch conducts the current, from the physical quality of inductor, we can write the equation as in (1-3).

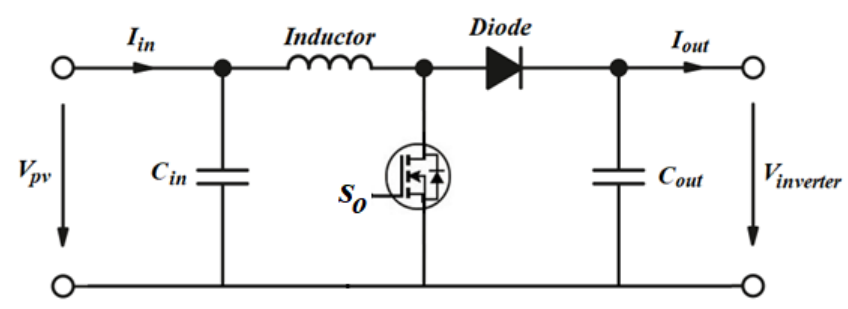

Figure 4. Boost converter control circuit

$$
\begin{aligned}
& V_{S}=V_{L}=0 \\
& V_{L}=V_{S}=L \frac{d i_{L}}{d t} \\
& \frac{d i_{L}}{d t}=\frac{V_{S}}{L}
\end{aligned}
$$


While the switch conducts the current $d i=\Delta T$, and the constant change of current considering the addition of electric current as linear, the equation follows:

$$
\begin{gathered}
\frac{\Delta i_{L}}{\Delta t}=\frac{\Delta i_{L}}{\Delta T}=\frac{V_{S}}{L} \\
\Delta i_{L, o n}=\frac{V_{S} \Delta T}{L}
\end{gathered}
$$

$\Delta i_{L, \text { on }}$ Means the rate of change of electricity in the inductor while the switch conducts the current.

While the switch does not conduct current, the current in the inductor cannot change immediately. The diode forwarding in conducting process, so the current flows through the inductor continuously. Assuming the voltage at the output side is constant, from the Kirchhoff's law, we can write the equation for the voltage across the inductor as in (6-8).

$$
\begin{aligned}
& -V_{S}+V_{L}+V_{o}=0 \\
& V_{L}=L \frac{d i_{L}}{d t} \\
& \frac{d i_{L}}{d t}=\frac{V_{S}-V_{o}}{L}
\end{aligned}
$$

While the switch does not conduct the current $d t=(1-D) T$, the rate of change of the current flowing through the inductor is constant. The decrease in the current is linear, allowing the new equation is

$$
\Delta i_{L, o f f}=\left[\frac{V_{S}-V_{o}}{L}\right](1-D) T
$$

The constant state of change in the current flowing through all the inductors is equal to zero, from the (5) and (9), we can write a new (10).

$$
\Delta i_{L, o n}+\Delta i_{L, o f f}=0
$$

\subsection{Power control method with hysteresis}

The three-phase inverter is used for the connection between wind turbines and generators through the boost converter circuit to supply non-linear loads and to connect to the grid. The selection of inverters is essential in controlling the power provided to the system. In this research, control methods use the current flow control technique. This method can return energy to the grid. The reference signal consists of a sine voltage reference signal $\left(V_{\text {ref I, 2,3 }}\right)$, a current reference signal flow to the network $\left(I_{\text {ref } 1,2,3}\right)$, and the output voltage reference signal of the generator $\left(V_{r f}\right)$. All three parts are just a reference signal that generates signals, to create the PWM signal for the switch to the hysteresis current control for the inverter with a diagram of the principle as shown in Figure 5.

\subsection{Principles of feedback control systems}

Types of controls that are common in industrial applications generally consist of Proportionalintegral-derivatives (PID controller) and the discrete output controller is a widely used feedback control system. The used value in the calculation is the error value derived from the difference in the process variables and the desired amount to the minimum by adjusting the input signal value of the process. The number of variants of the used PID must change according to the nature of the system. The calculation method of the PID depends on three variables: the proportion, integrals, and derivatives. The result of the current error determines the equal values, and the integral value determined by the result based on the sum of the mistakes which just passed, and the derivative value based on the change rate of the error value, the weight resulting from these three combinations must use to adjust the process. Adjusting the constants in the PID The controller can change the control pattern to suit the process requirements, the response of the controller is in the form of the control of the body until the error (overshoots) and system swing (oscillation). The PID method does not guarantee that it is the most appropriate control system or can

Development of DC voltage control from wind turbines using proportions... (Arckarakit Chaithanakulwat) 
make the process stable. Applications may sometimes use only one to two forms depending on the process. Sometimes PIDs are referred to as PI, PD, P or I control depending on the implementation. For this research, the PI must be used to control the voltage of the boost converter; the proportional response can make by multiplying the error with the $K_{p}$ constant, also known as the magnification ratio. For integrative terms, the proportion of error size and duration of failure, the sum of errors in every period must give the accumulated offset that should be in the previous. The cumulative error is multiplied by the integration rate. The integration rate $K_{i}$ determines the size of the result of the integral term, as in Figure 2.

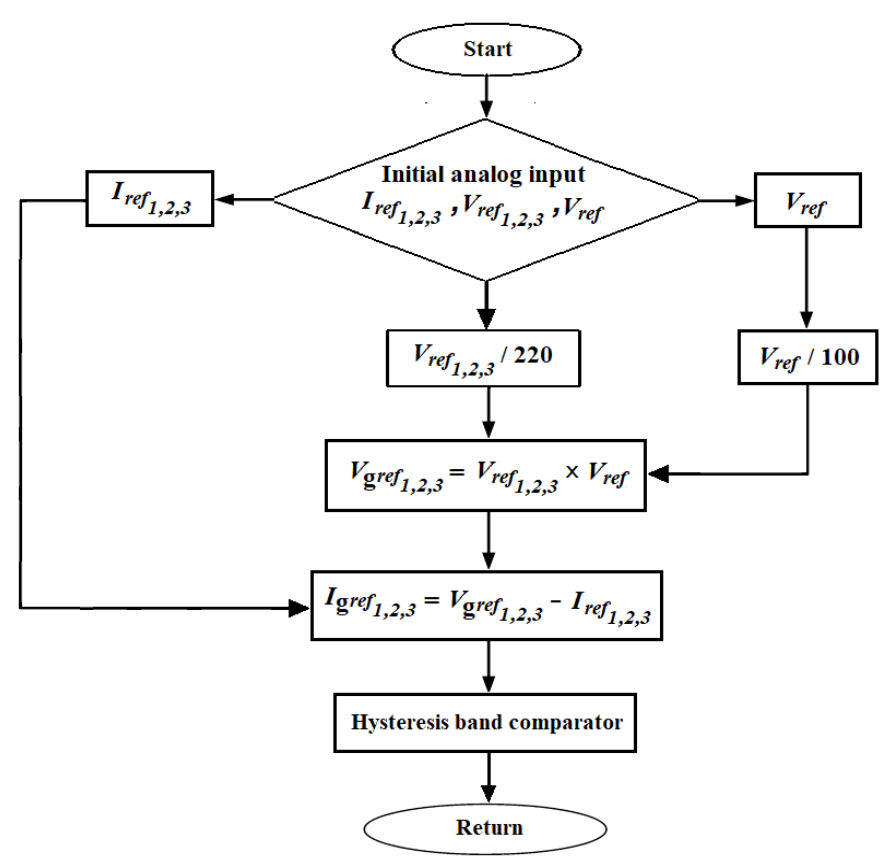

Figure 5. Diagram of the calculation reference current

\section{RESULTS AND DISCUSSION}

In this research, boost converter test, full system prototype testing and non-linear load testing are as follows. For testing, a boost converter uses proportional and integral control techniques to control VDC voltage levels. The test performed by maintaining a constant voltage in conditions as varying the input voltage from wind turbines or Vwind generators and as increasing the number of loads, the test results shown in Figure 6 (a) and (b).

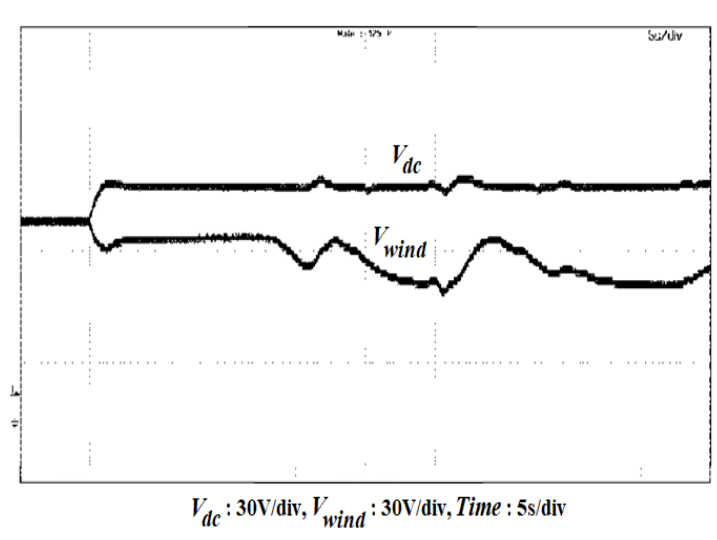

(a)

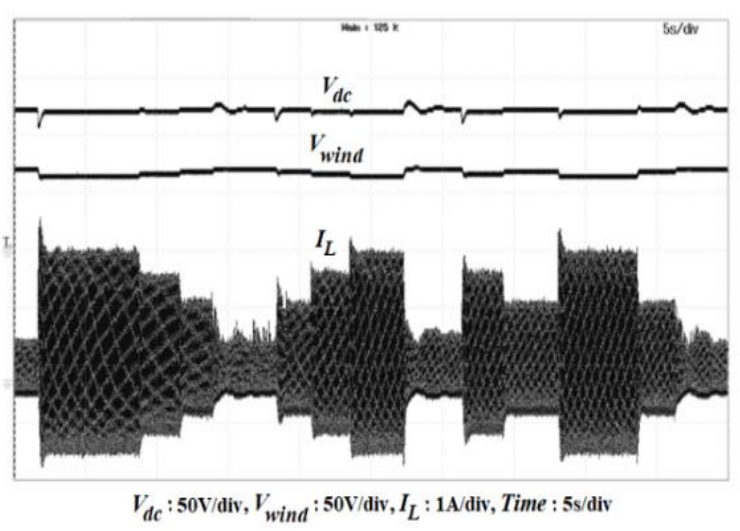

(b)

Figure 6. Boost Converter testing using PI techniques 
Based on the test results from Figure 6. (a), we found that the boost converter circuit is controlled by the proportional and integral control techniques with changing conditions, input voltage ranging can control constant voltage and the signal ripple is not more than $5 \%$. Based on the test results from Figure 6. (b), while changing conditions of load, it can control the voltage level as needed. Testing of three-phase inverters controls the current by using a hysteresis control technique, and by testing the current amplitude to supply power to the three-phase grid-connected system. The prototype scheme in Figure 7, in the case of voltage changes on the input side of a wind turbine or generator size, test results showed that the threephase inverter circuit, with current control using a hysterical control technique, can increase the current size for supplying power to the electrical network system according to the change of input voltage from wind turbines or generators.

This research, presented above, creates a prototype and test the voltage control system of the boost converter circuit using proportional and integral control techniques. Including, checking the current control of the three-phase inverter circuit, using a current control technique hysteresis to supply non-linear load together with the power supply into the grid-connected system. From the comparison of simulation results with programs, MATLAB/Simulink with the sample time of $10 \mu$ s are shown in Figure 8 (a) and (b). Figure 8 (a) is shown changes in voltage and the amplitude of the current flow for testing the integrated system. It must be tested using wind turbines or generators. It is using the boost converter circuit to maintain the voltage level and to use the 3-phase inverter circuit to supply power to the grid. The voltage from the wind turbine, there must be changes to adjust the size of the current to the grid, according to the proportion of the tension and maintain a constant DC bus voltage. From the system test in Figure 8 (b), it was found that the boost converter circuit could maintain the voltage level higher than the fixed grid, and will able to adjust the amplitude of the grid-connected according to the power of the wind turbine produced the signal.

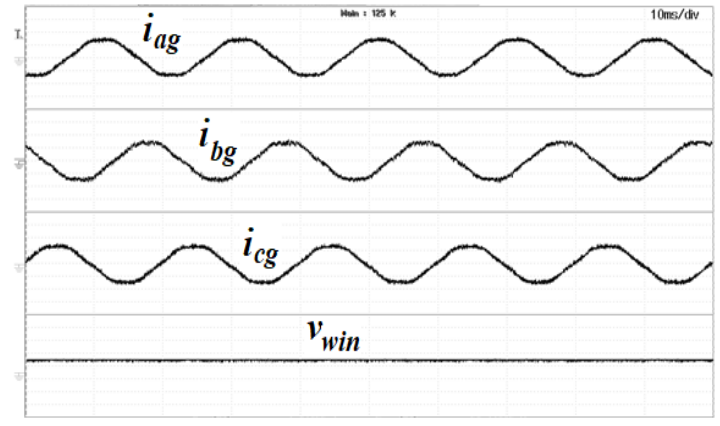

(a)

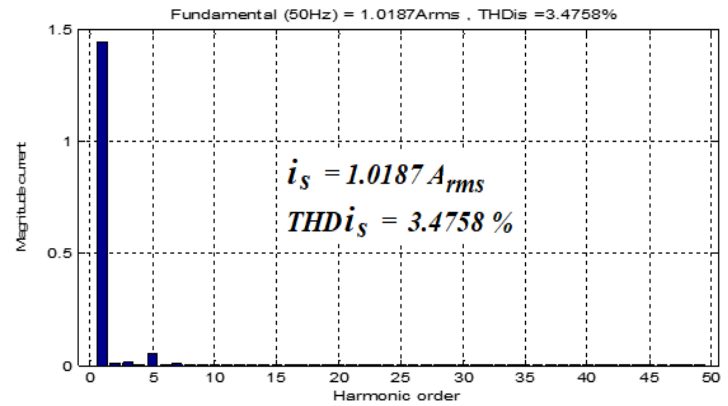

(b)

Figure 7. The current grid-connected

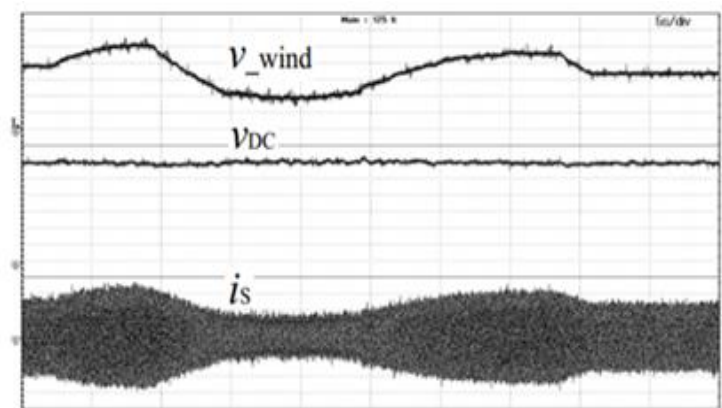

$v_{-}$wing $: 20 \mathrm{~V} / \mathrm{div}, v_{\mathrm{DC}}: 20 \mathrm{~V} / \mathrm{div}, i \mathrm{~s}: 500 \mathrm{~mA} / \mathrm{div}$, Time $: 5 \mathrm{~s} / \mathrm{div}$

(a)

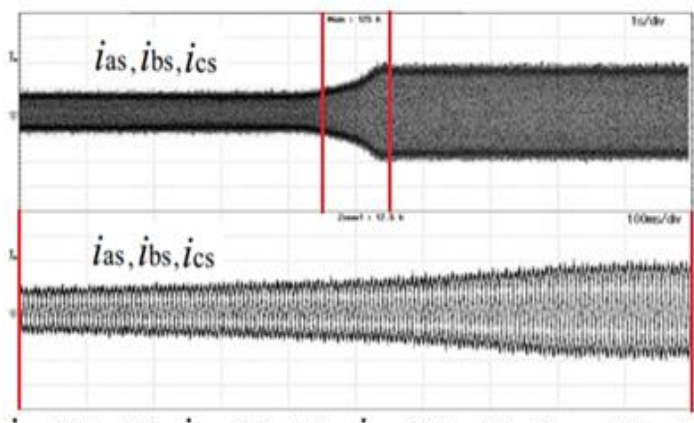

$i_{\text {as: }}: 500 \mathrm{~mA} / \mathrm{div}, i_{b s}: 500 \mathrm{~mA} / \mathrm{div}, i \mathrm{cs}: 500 \mathrm{~mA} / \mathrm{div}$, Time : $100 \mathrm{~ms} / \mathrm{div}$

(b)

Figure 8. Changes in voltage and current size

Based on the test results, Figure 9 and Figure 10, found that the three-phase inverter circuit with current control using the hysterical control technique, it can increase the current size of the power supply into the power network system, according to the change of input voltage from wind turbines, and the value of $\mathrm{THD} i_{s}$ is reduced according to the increasing current size as simulated in MATLAB/Simulink. System

\footnotetext{
Development of DC voltage control from wind turbines using proportions... (Arckarakit Chaithanakulwat)
} 
testing with the non-linear load must be a non-linear load with the grid, which the three-phase electric wind turbine connection system must help the power grid supply the non-linear load together with the power at the wind turbine or the generator can produce the output. Also, this system helps to solve the harmonic problems that occur in the system, depending on the energy received and testing with non-linear loads.

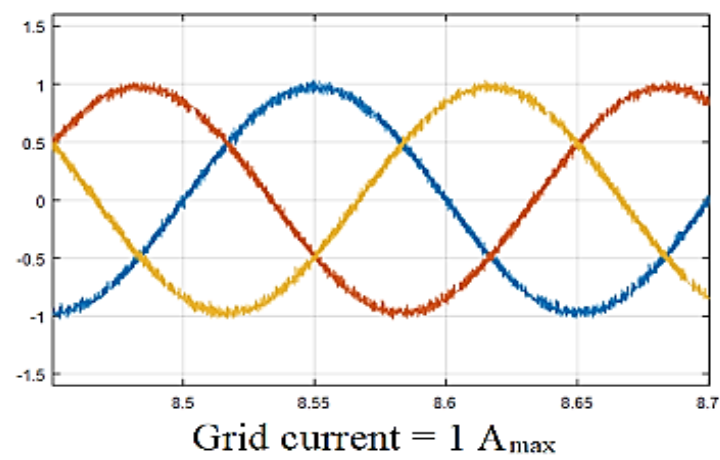

(a)

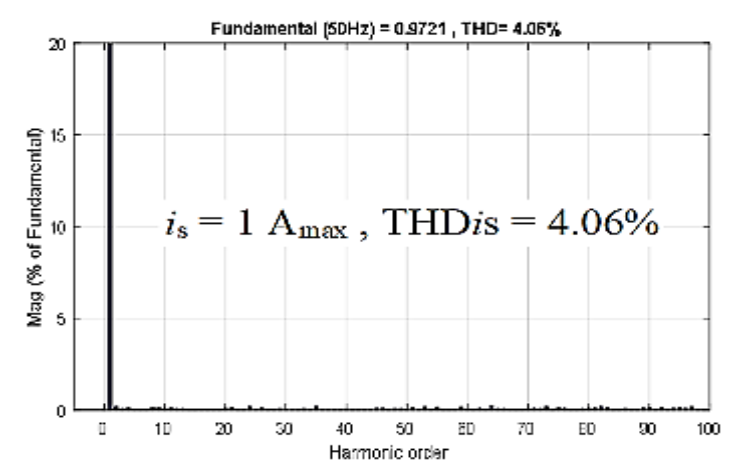

(b)

Figure 9. Distortion of current simulated in MATLAB/Simulink

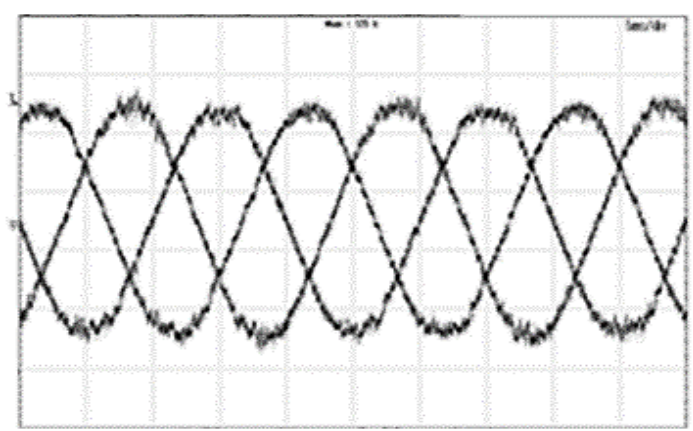

(a)

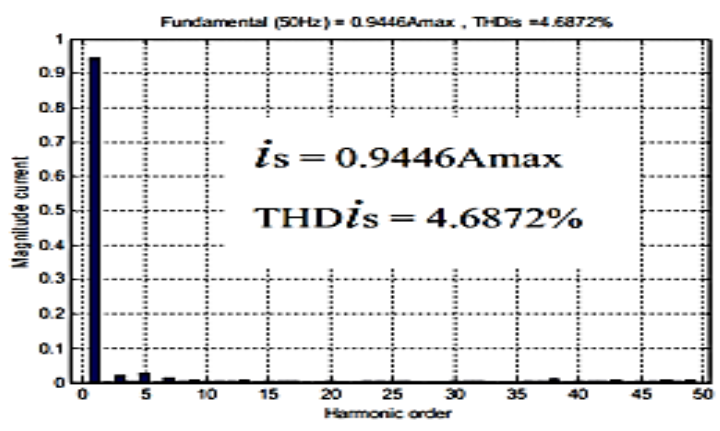

(b)

Figure 10. Distortion of the current prototype

Figure 11 (a) and (b) based on system test results and simulation results in MATLAB/Simulink and compare with Figure 12 (a) and (b), we found that the load current can be used to pay for the load instead of the grid and can supply power to enter the system with the low distortion of THD $i_{s}$ waveforms. Figure 13, it was shown that the load current and current grid-connected to control by conditions, $i_{c}=i_{s}+i_{L}$ in the case of a step load test.

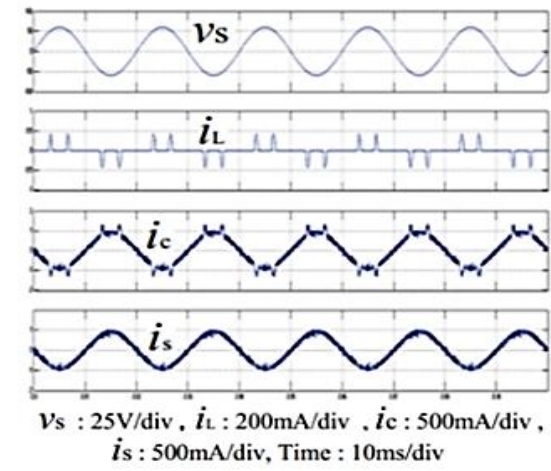

(a)

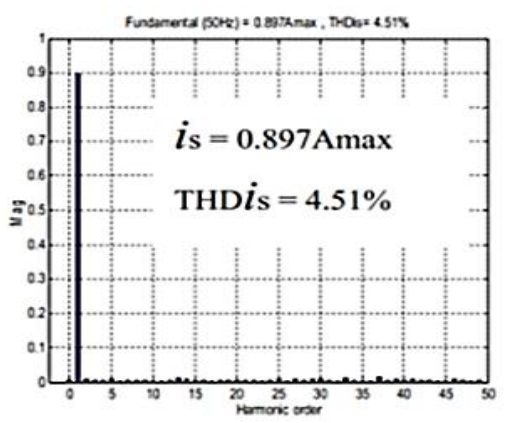

Figure 11. Current distortion in the non-linear load from MATLAB/Simulink 

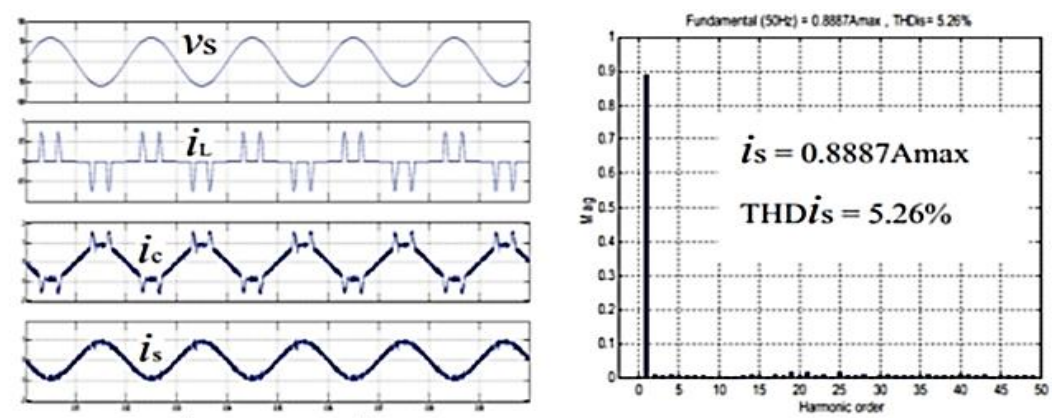

$v_{\mathrm{s}}: 25 \mathrm{~V} / \mathrm{div}, i_{\mathrm{L}}: 200 \mathrm{~mA} / \mathrm{div}, i_{\mathrm{c}}: 500 \mathrm{~mA} / \mathrm{div}$,

$i_{\mathrm{s}}: 500 \mathrm{~mA} / \mathrm{div}$, Time $: 10 \mathrm{~ms} / \mathrm{div}$

(b)

Figure 11. Current distortion in the non-linear load from MATLAB/Simulink (continue)

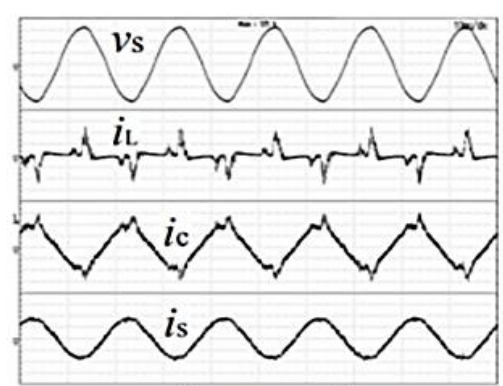

$v_{\mathrm{s}}: 25 \mathrm{~V} / \mathrm{div}, i_{\mathrm{L}}: 200 \mathrm{~mA} / \mathrm{div}, i_{\mathrm{c}}: 500 \mathrm{~mA} / \mathrm{div}$, $i_{\mathrm{s}}: 500 \mathrm{~mA} / \mathrm{div}$, Time : $10 \mathrm{~ms} / \mathrm{div}$

(a)

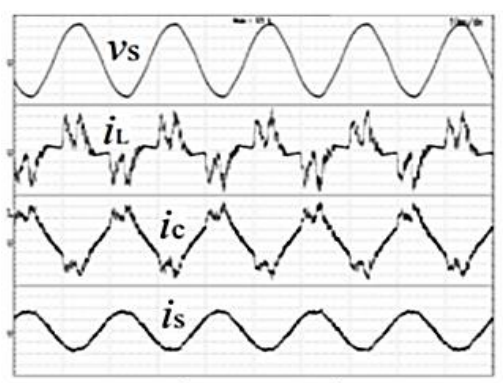

$v_{\mathrm{s}}: 25 \mathrm{~V} / \mathrm{div}, i_{\mathrm{L}}: 200 \mathrm{~mA} / \mathrm{div}, i_{\mathrm{c}}: 500 \mathrm{~mA} / \mathrm{div}$, $i \mathrm{~s}: 500 \mathrm{~mA} / \mathrm{div}$, Time : $10 \mathrm{~ms} / \mathrm{div}$
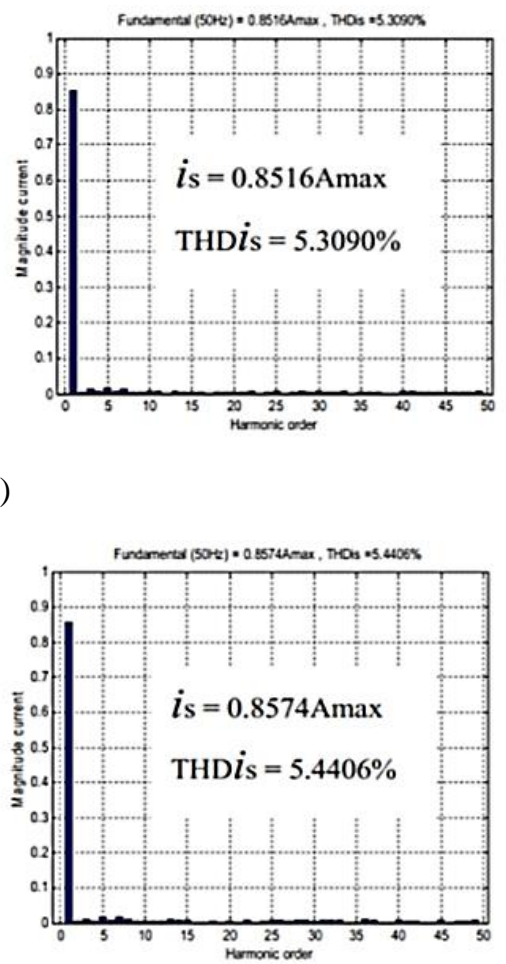

(b)

Figure 12. Current distortion $i_{s}$ in non-linear load from the prototype

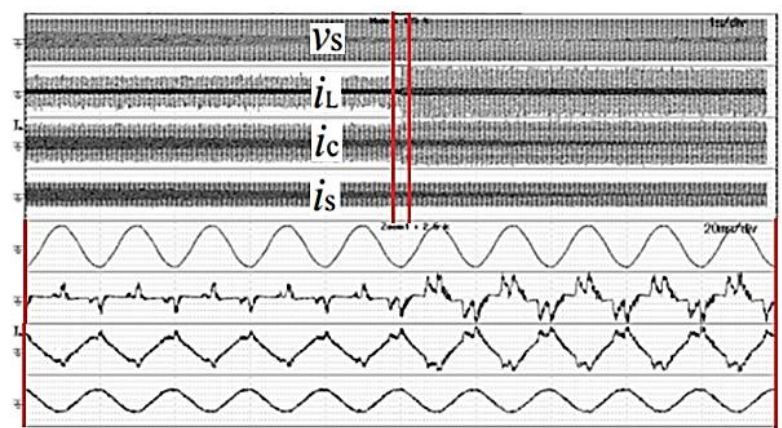

$v_{\mathrm{s}}: 25 \mathrm{~V} / \mathrm{div}, i_{\mathrm{L}}: 200 \mathrm{~mA} / \mathrm{div}, i_{\mathrm{c}}: 500 \mathrm{~mA} / \mathrm{div}, i_{\mathrm{s}}: 500 \mathrm{~mA} / \mathrm{div}$, Time $: 10 \mathrm{~ms} / \mathrm{div}$

Figure 13. Test results for non-linear load step 


\section{CONCLUSION}

Based on the above research is found that the boost converter circuit is to maintain voltage levels and control on the three-phase inverter circuit for power transmission into the 3-phase power network system for wind turbines and to able to track the power from the wind turbine. The Boost Converter circuit has a signal ripple in case, there is a change in the input voltage not more than 5\%. Also, for the power supply, the THDi value is reduced by decreasing the size of the current to the electricity network. Moreover, we found that the load current can be modified to solve the harmonics in the system according to the conditions and the average system efficiency is $87.25 \%$, including the average distortion of the current waveform in the order, is not more than $5 \%$.

\section{ACKNOWLEDGEMENTS}

This work was supported by the Dhonburi Rajabhat University, Thailand. The authors would like to thank Prof. Vijit Kinnares, consulting this research, Mr. Attakarn Anakavanic and Mr. Sakdawut Boontua for the experimental setup

\section{REFERENCES}

[1] A. B. Raju, B. G. Fernandes, K. Chatterjee, "A UPF power conditioner with maximum power point tracker for grid-connected variable speed wind energy conversion system," Proc. of 1st International Conf. on Power Electronics Systems and Applications (PESA 2004), Bombay, India, 1: 107-112, 2004.

[2] Dalala, Z. M., Zahid, Z. U., Yu, We, Cho, Y., and Lai, J.-S., "Design and Analysis of an MPPT technique for small- scale wind energy conversion systems," IEEE Energy Convers, 28(3); 756-767, 2013.

[3] Arckarakit Chaithanakulwat, "Track the maximum power of a photovoltaic to control a cascade five-level inverter a single-phase grid-connected with a fuzzy logic control," International Journal of Power Electronics and Drive System (IJPEDS), 10(4); 1863-1874, 2019.

[4] Wannakarn, P., and V. Kinnares," Digital Signal Controller-Based Grid-Connected Inverter for Axial Flux Permanent Magnet Generator," In 2011 IEEE Ninth International Conference on Power Electronics and Drive Systems (PEDS), Singapore, 1527-1530, 2011.

[5] Ramasamy B. K., Palaniappan A., "Yakoh S. M. Direct-drive low-speed wind energy conversion system incorporating axial-type permanent magnet generator and Z-source inverter with sensorless maximum power point tracking controller, ” IET Renew. Power Generat, 7(3); 284-295, 2013.

[6] R. David Richardson and Gerald M McNerney. "Wind Energy Systems. Proceedings of the IEEE," 81(3); 378-389, 1993.

[7] Gary L Johnson, “Wind Energy Systems, ” Prentice Hall Inc. Englewood Cliff. NJ. 1985.

[8] R. M. Hiloowala and A. M. Sharaf., "A utility-interactive wind energy conversion scheme with an asynchronous dc-link using a supplementary control loop," IEEE Tran.on Energy Conver., 9(3); 558-563, 1994.

[9] Ghaffari, A., Krstic, M., and Seshagiri, S., "Power optimization and control in wind energy conversion systems using extremum seeking," IEEE Trans. Control Syst. Technol., 22(5); 1684-1695, 2014.

[10] Larbi M'hamed, Gherabi Zakaria, Doudar Khireddine, "A Robust Sensorless Control of PMSM Based on Sliding Mode Observer and Model Reference Adaptive Syste," International Journal of Power Electronics and Drive System (IJPEDS), 8(3); 1016-1025, 2017.

[11] S. M. Muyeen, A. Al-Durra, J. Tamura, "Variable speed wind turbine generator system with current controlled voltage source Inverter. Energy Conversion and Management," 52(7); 2688-2694, 2011.

[12] Mesemanolis A., Mademlis C., and Kioskeridis I, "Optimal efficiency control strategy in wind energy conversion system with induction generator,” IEEE J. Emer. Select. Topics Power Electron, 1(4); 238-246, 2013.

[13] Nazha Cherkaoui, Touria Haidi, Abdelaziz Belfqih, Faissal El Mariami, Jamal Boukherouaa, "A Comparison Study of Reactive Power Control Strategies in Wind Farms with SVC and STATCOM," "International Journal of Electrical and Computer Engineering (IJECE)," 8(6); 4836-4846, 2018.

[14] A. Masmoudi, L. Krichen, A. Ouali, "Voltage control of a variable speed wind turbine connected to an isolated load: Experimental study," Energy Conversion and Management, 59(1); 19-26, 2012.

[15] X. Wang, S. Yuvarajan, L. Fan, "MPPT control for a PMSG-based grid-tied wind generation system," In North American Power Symposium (NAPS), 1-7, 2010.

[16] Z. Qiu, K. Zhou, Y. Li. "Modeling and control of diode rectifier fed PMSG based Wind turbine in Electric Utility Deregulation and Restructuring and Power Technologies (DRPT)," 4th International Conference on, 1384-1388, 2011.

[17] M. Zhou, G. Bao, Y. Gong, "Maximum power point tracking strategy for direct-driven PMSG," in Power and Energy Engineering Conference (APPEEC), Asia-Pacific, 1-4, 2011.

[18] M. E. Haque, M. Negnevitsky, K. M. Muttaqi, "A novel control strategy for a variable speed wind turbine with a permanent magnet synchronous generator," Industry Applications Society Annual Meeting, IAS'08, IEEE. 1-8, 2008.

[19] M.-G. Daniel, A.-M. Omar, T.-O. Rubén, G.-B. Abel, "Comparison of Different PLL Strategies for Applications in a Wind Generation System. Procedia Technology, 7(1) 150-157, 2013. 
[20] S.Chandra Shekar, G.Ravi Kumar, S.V.N.L Lalitha, "A transient current based micro-grid connected power system protection scheme using wavelet approach," International Journal of Electrical and Computer Engineering (IJECE), 9(1); 14-22, 2019.

[21] Seyed Mohsen Mousavi Khormandichali, Mehrdad Ahmadi Kamarposhti, "Optimal placement of wind generation units in order to increase revenues and reduce the imposed costs in the distribution system considering uncertaint," International Journal of Electrical and Computer Engineering (IJECE), 9(6); 4524-4539, 2019.

[22] Rajin M. Linus, Perumal Damodharan, "Wind Velocity Sensorless Maximum Power Point Tracking Algorithm in Grid-connected Wind Energy Conversion System, “Journal Electric Power Components and Systems," 43(15); 1761-1770, 2015.

[23] A. Chaithanakulwat, V. Kinnares, N. Thungsuk, "Modeling and Simulation of a 3-Phase Grid-Connected Photovoltaic Inverter with Active Power Filter Functionality for Harmonic Mitigation," The International Conference on Electrical Engineering (ICEE 2012), Kanazawa, 186-190, 2012.

[24] A. Chaithanakulwat, V. Kinnares, N, "Thungsuk. Single-Phase Grid-Connected Photovoltaic System with Active Power Filter Functionality," In 2012 15th International Conference on Electrical Machines and System (ICEMS), Sapporo, IEEE. 175-177, 2012.

[25] Arckarakit Chaithanakulwat, Vijit Kinnares, "Implementation of a Low-cost Single-phase Grid-Connected Photovoltaic System with Active Filtering Mechanism," International Review of Electrical Engineering (IREE), 12(2); 175-182, 2017.

[26] S. Raja Mohamed, P. Aruna Jeyanthy, D. Devaraj, "Hysteresis-based Voltage and Current Control Techniques for Grid Connected Solar Photovoltaic Systems: Comparative Study, "International Journal of Electrical and Computer Engineering (IJECE), 8(5); 2671-2681, 2018.

[27] Semaria Ruiz, Julian Patino, Jairo Espinosa1, "PI and LQR controllers for Frequency Regulation including Wind Generation," International Journal of Electrical and Computer Engineering (IJECE), 8(5); 2771-2721, 2018.

[28] Chandra Shekher Purohit, Geetha M., P. Sanjeevikumar, Pandav Kiran Maroti, Shruti Swami, Vigna K. "Ramachandaramurthy. Performance analysis of DC/DC bidirectional converter with sliding mode and pi controller," International Journal of Power Electronics and Drive System (IJPEDS), 10(1); 357-365, 2019.

\section{BIOGRAPHY OF AUTHOR}

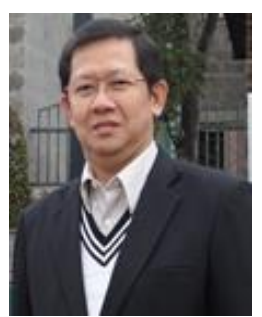

Arckarakit Chaithanakulwat He received the B.Ind.Tech.degree in Electrical engineering from South-East Asia University, Bangkok, Thailand, in 1993, M.Eng. Degree in electrical engineering from king Mongkut's Institute of Technology Ladkrabang, Bangkok, Thailand, in 1998, and D.Eng. Degree in electrical engineering from king Mongkut's Institute of Technology Ladkrabang, Bangkok, Thailand, in 2017. His research interests include renewable energy systems, power electronics, motor drives and application of power electronic in system. 